\title{
CONEXÕES PERIFÉRICAS NO PENSAMENTO DE JOSÉ CARLOS MARIÁTEGUI (1920-1930)
}

\author{
PERIPHERAL CONNECTIONS IN THE THOUGHT OF JOSÉ \\ CARLOS MARIÁTEGUI (1920-1930)
}

Karina Oyakawa ${ }^{1}$

RESUMO:A produção intelectual do socialista peruano José Carlos Mariátegui (1894-1930) abrange, além de suas análises sobre o Peru, o estudo do panorama internacional - incluindo não somente a Europa, mas a Ásia ea África (Oriente), como também a América Latina. Assim, uma das faces de seu pensamento parece resultar do exame da situação de países periféricos após a Primeira Guerra Mundial, e das possíveis conexões, em termos de circulação de ideias, existentes entre eles nesse período, particularmente na década de 1920. A presente nota de pesquisa objetiva apresentar o desenvolvimento da dissertação de mestrado sob o título "Conexões periféricas no pensamento de José Carlos Mariátegui", que tem a intenção de compreendercomo a aproximação a essas formações culturais diferentes contribuiu para a elaboração das ideias do intelectual peruano.

PALAVRA-CHAVE: Anos 1920; José Carlos Mariátegui; Ocidente-Oriente; Pensamento latino-americano.

ABSTRACT:The intellectual production of the Peruvian socialist José Carlos Mariátegui (1894-1930) includes, in addition to his analysis of Peru, the study of the international panorama - including not only Europe, but Asia and Africa (East), as well as Latin America. Thus, one of the sides of his thought seems to result from the examination of the situation of peripheral countries after the World War I, and of the possible connections, in terms of the circulation of ideas, existing between them in this period, particularly in the 1920s. The objective of this research is to present the development of the master's thesis under the title "Peripheral connections in the thought of José Carlos Mariátegui", which intends to understand how the approach to these different cultural formations contributed to the elaboration of the ideas of the Peruvian intellectual.

\footnotetext{
* Pesquisa decorrente do mestrado, desenvolvido na Universidade Federal de São Paulo, com financiamento Capes.

${ }^{1}$ Mestranda do Programa de pós-graduação em História da Universidade Federal de São Paulo (UNIFESP). Email: karinaoyakawa@gmail.com
} 
KEYWORDS: 1920s; José Carlos Mariátegui; West-East; Latin American thought.

Introdução

O socialista peruano José Carlos Mariátegui (1894-1930)é geralmente valorizado pela historiografia por ter desenvolvido um pensamento latinoamericano original face às ideias marxistas e socialistas correntes nas primeiras décadas do século XX. Para vários autores, um marxismo autóctone somente encontraria no intelectual a sua formulação, considerando-o, na denominação de AntonioMelis(1979), o "primer marxista de America". Alcançou esse lugar no pensamento internacional, principalmente por aproximar o materialismo histórico à realidade majoritariamente indígena do Peru, almejando na confluência entre eles a possibilidade de construção de um projeto nacional por meio da via socialista.Atribuiu aos indígenas um papel fundamental para a revolução socialista peruana, como parte da camada produtiva da sociedade. Inserindo-os, dessa forma, em outra análise que não a das interpretações eurocêntricas, e formulando um discurso alternativo ao dos poderes institucionalizados (ALIMONDA, 1994: 110).

Um segundo ponto de recorrente interesse em suas ideias é o relacionado ao imperialismo. Devido à formação nacional peruana, a classe dirigente burguesa se aliava ao domínio estrangeiro, em detrimento de uma maior coesão entre as camadas sociais. Essa aliança alimentava a dependência e sua ruptura somente seria realizada, segundo Mariátegui, mediante uma revolução socialista. Essa solução era corroborada pelo momento de crise após a Primeira Guerra Mundial, no qual conceitos como democracia, estavam sendo questionados, como formadores da cultura burguesa capitalista.

As ideias de Mariátegui circulam na América Latina através da divulgação por estudiosos de seu pensamento e pela atuação de movimentos sociais que têm no intelectual uma de suas referências. No Brasil, ainda foram influências para uma sociologia crítica e se aproximaram de formulações 
teóricas, como a Teoria da dependêncianos anos 1960-1970 (LÖWY, 2006: $13)^{2}$.

A pesquisa, "Conexões periféricas no pensamento de José Carlos Mariátegui (1920-1930)", é um desdobramento de um estudo anterior que analisou a produção brasileira acerca das ideias de Mariátegui, percorrendo desde a década de 1970 até os anos $2000^{3}$. Com um caráter de revisão historiográfica, foi realizado um levantamento da bibliografia sobre o socialista, o que possibilitou depreender aspectos pouco explorados de seu pensamento.Acreditamos que enquanto a criação do socialismo "indoamericano" é melhor examinada pelos pesquisadores, uma visão mais abrangente do intelectual,considerando sua análise sistêmica da conjuntura dos anos 1920, não recebeu os mesmos cuidados pela historiografia.

Contemporânea ao período de crise do Ocidente após a Primeira Guerra Mundial, a obra de Mariátegui abrange, além de sua interpretação da realidade peruana, a análise do panorama mundial, incluindo não somente a Europa, mas a África e a Ásia (Oriente), como também, a América Latina. Assim, uma das faces de seu pensamento parece resultar do exame da situação de países periféricos no pós-guerra, e das possíveis conexões, em termos de circulação de ideias, existentes entre eles nesse período, particularmente na década de 1920.Levando-se em consideração que Mariátegui, a partir de suas análises sobre o contexto nacional peruano, é apontado como referência para os estudos de países periféricos e de característica dependente, essa constatação aponta para uma lacuna sobre esseaspecto de seu pensamento.

Partindo dessa hipótese, acreditamos que o pensamento do intelectual peruano, considerado síntese criativa entre uma visão eurocêntrica e uma excepcionalidade latino-americana, na conhecida fórmula de Löwy (2006: 102), ganha maior complexidade, ao se dar atenção para outras formações

\footnotetext{
${ }^{2}$ Data da década de 1970 o início, no Brasil, de uma produção analítica acerca de Mariátegui, embora realizada de forma bem pontual. Destaca-se do período o prefácio que Florestan Fernandes escreveu em 1974 aos Sete ensaios de interpretação da realidade peruana, no qual evidencia a importância de Mariátegui para os anos de Regime militar no Brasil.

${ }^{3}$ A monografia intitulada "Nossa necessidade de infinito: leituras sobre José Carlos Mariátegui no Brasil" foi defendida no Departamento de História da Universidade Federal de São Paulo no ano de 2017.
} 
culturais no seu processo de criação do socialismo "indo-americano". Em vista disso, nossa intenção é compreendercomo as possíveis conexões entre Peru e Oriente, presentes em sua produção e amparadas pela conjuntura do período, contribuíram para a elaboração de suas ideias, tendotambém como premissa, a dialética entre o seu internacionalismo e suas preocupações com o nacional.

Para tanto, elegemos como fontes de análise seus artigos e ensaios publicados em periódicos da época como o Mundial e Variedades, e que percorrem o período de sua formação marxista na Europa e sua posterior volta ao Peru ${ }^{4}$.

Jornalista autodidata, Mariátegui refletiu sobre os principais acontecimentos do início do século XX, período que considerou como um dos "más singularmente intensos y agitados de la historia mundial" (MARIÁTEGUI, 1986a: 175).Acompanhou os desdobramentos das revoluções mexicana, chinesa e russa, o surgimento do fascismo, além de movimentos nacionalistas e anti-imperialistasnascidos na África e na Ásia. O intelectual discutiu ainda conflitos e processos políticos latino-americanos, como o caudilhismo e os sistemas eleitorais (AQUINO BOLAÑOS, 2000: 443). Como um atento crítico, formulava interpretações desse panorama, inserindo o Peru em suas proposições regionais (latino-americanas) ou globais. A exemplo, a marcha fascista sobre Roma, "não apenas simbolizava para ele o fracasso da resposta capitalista às perspectivas revolucionárias como também recordava-lhe atitudes elitistas de seu próprio país" (MORSE, 1988: 107).

No horizonte pós-guerra, a imagem do derrocamento da civilização burguesa foi sentida e comentada por diversos intelectuais ${ }^{5}$, como por Oswald Spengler (que publicou a obra A decadência do Ocidente em 1918). Vivenciando mais de três anos o cenário europeu, Mariátegui defendeu que estava ocorrendo o "crepúsculo da civilização ocidental” (MARIÁTEGUI,

\footnotetext{
${ }^{4}$ A interferência de Mariátegui na política, não somente por meio de seu ofício de jornalista, como também por sua inserção nos movimentos sociais, custou-lhe um exílio na Europa (19191923), que o aproximou da cena cultural e política internacional, permitindo ainda o seu aprofundamento nos estudos do marxismo. Mariátegui afirmaria posteriormente que foi na Europa onde teve seu maior aprendizado.

${ }^{5}$ Para o caso latino-americano, cf. Compagnon, 2014.
} 
2012: 49-54), consequência do fracasso do capitalismo e da democracia, sendo o fascismo um dos seus sintomas. Ademais, indicava a falta de um mito capaz de reerguer a sociedade burguesa ${ }^{6}$. Por outro lado, vislumbrou com a Revolução Russa a possibilidade de surgimento de uma nova civilização, tendo as áreas periféricas importância como parte do processo. Assim, as noções de "crise" e "revolução" orientam suas análises, sendo relevantes para pensarmos em sua interpretação do contexto.

As potências europeias, minadas por uma crise econômica, política e social, perdiam o controle de suas posições no Oriente, que se sublevava por sua independência, com o apoio da Rússia revolucionária. Podemos perceber a importância que essa região assume nas análises de Mariátegui quando afirma, por exemplo:"La marea revolucionaria no conmuevesóloalOccidente. También el Oriente está agitado, inquieto, tempestuoso. Uno de los hechos más actuales y trascendentes de la historia contemporánea es la transformación política y social del Oriente" (MARIÁTEGUI, 1975: 190).

$\mathrm{Na}$ América Latina, a crise correspondia ao questionamento das repúblicas oligárquicas, aliadas do imperialismo, e dos regimes feudais que ainda sobreviviam na região. No Peru, as expressões do feudalismo eram o latifúndio e a servidão, que prendiam os indígenas a esse sistema econômico desde a colonização. Por isso, a luta dos indígenas correspondia à luta pela terra. Segundo Mariátegui, as elites após a independência foram incapazes, dentro de princípios liberais e capitalistas, de pôr fim a exploração indígena,

\footnotetext{
${ }^{6}$ Expressou Mariátegui: "La crisis de la civilización burguesa apareció evidente desde el instante en que esta civilización constato su carência de un mito. [...] Lo que más neta y claramente diferencia en esta época a la burguesía y al proletariado es el mito. La burguesía no tiene ya mito alguno. Se ha vuelto incrédula, escéptica, nihilista. El mito liberal renacentista, ha envejecido demasiado. El proletariado tiene un mito: la revolución social" (MARIÁTEGUI, 1970: 19 e 23).A presença do mito em seu pensamento, influência do sindicalista Georges Sorel, demonstra o espaço que suas ideias abrem para certa subjetividade, sendo esta encontrada também em seu interesse pelas vanguardas artísticas. Em seus artigos há a crítica da racionalidade moderna, sintomático da conjuntura posterior à Primeira Guerra Mundial. Entretanto, sua subjetividade não se afasta da preocupação com a realidade material, formulando de maneira dialética: "El materialismo socialista encierra todas lasposibilidades de ascensión espiritual, ética y filosófica. Y nunca nos sentimos más rabiosa y eficaz y religiosamente idealistas que al asentar bien la idea y los pies en la matéria" (MARIÁTEGUI, 1986b: 250).
} 
que por sua vez, impedia o desenvolvimento nacional. Dessa forma, o caminho para a transformação social só poderia ser dado pelo socialismo.

Integrante da "vanguarda intelectual" 7 do período, Mariátegui procurou a valorização do indígena na sociedade peruana. Contudo, apresentou um esforço de conjugar a revolução no Peru com a revolução mundial, integrando o indígena e sua cultura no processo de transformação.Esse trecho possibilita a apreensão de aspectos da leitura que fazia de povos orientais e a aproximação com o movimento indigenista peruano. Mariátegui aponta sua consanguinidade em termos de propostas revolucionárias, por meio do mito da revolução socialista.

Não é a civilização, não é o alfabeto, o que levanta a alma do índio. É o mito, é a ideia da revolução socialista. A esperança indígena é absolutamente revolucionária. $\mathrm{O}$ mesmo mito, a mesma ideia são agentes decisivos no despertar de outros velhos povos, de outras velhas raças em colapso: indianos, chineses etc. Hoje, como nunca, a história universal tende a se reger pelo mesmo quadrante.

Por que o povo inca, que construiu o mais desenvolvido e harmonioso sistema comunista, haveria de ser o único insensível à emoção mundial? A consanguinidade do movimento indigenista com as correntes revolucionárias é demasiado evidente para que seja preciso documentá-la. Já disse que cheguei ao entendimento e à justa valorização do indígena pelo caminho do socialismo (MARIÁTEGUI, 2010: 53-54).

José Carlos Mariátegui, a América Latina e o Oriente

O socialismo concede ao pensamento de Mariátegui uma dimensão internacionalista ${ }^{8}$. Essa foi uma característica presente entre os intelectuais da América Latina dos anos 1920. Concomitantemente, no plano das ideias, o pensamento latino-americano se voltava para as particularidades do nacional.O que antes se discutia em termos de "civilização" e "progresso" da modernidade racional ocidental, homogeneizando a cultura, passava a ser questionado pelas realidades autóctones (MITRE, 2003: 40-41). Os acontecimentos do início do

\footnotetext{
7 "Vanguarda intelectual” em oposição à "elite intelectual”. Cf. WASSERMAN, 2015: 71-72.

${ }^{8}$ São vários os exemplos do caráter internacionalista, como o seguinte trecho: "Tenemoseldeber de no ignorar larealidad nacional; pero tenemostambién el deber de no ignorar larealidad mundial. El Perú es un fragmento de un mundo que sigue una trayectoria solidaria" (1986c: 38).
} 
século contribuíram para que essas novas ideias se manifestassem. A guerra favoreceu o desenvolvimento do pensamento latino-americano, com os intelectuais afastando seus olhares da Europa e buscando novas referências em um processo de construção, ou de reelaboração, da nacionalidade ${ }^{9}$. O parâmetro a ser seguido era o nacional e a figura do "bárbaro" foi mobilizada por muitos intelectuais para se referir aos povos do "Velho Continente", evidenciando uma reversão das relações de alteridade com a quebra de identidade cultural ${ }^{10}$.

Para estudiosos do marxismo como José Aricó (1989: 436), a experiência bélica, juntamente com a Revolução de Outubro, teve ressonâncias no mundo não-europeu, apontando para a possibilidade de transformações mesmo na ausência de plenas condições de desenvolvimento. Destarte, se a crise da Europa, posterior a guerra finda em 1918, afastou os latino-americanos do espelho de suas antigas metrópoles, os processos revolucionários de outubro do ano anterior (como proposta de revolução) e o imperialismo (assim como o anti-imperialismo)aproximaram contextos civilizatórios diferentes, situados nas áreas periféricas. Isso é uma novidade dos anos 1920 (FUNES, 2006: 229), e trouxe maior densidade à discussão sobre a identidade latino-americana e sobre o lugar que ocupava no arranjo mundial.

O decênio de 1920 é considerado pela historiografia latino-americana como de anos de transição. Como caracteriza a historiadora argentina Patrícia Funes (2006: 13), que se debruçou sobre a década, “todo está 'como por ser' o despidiéndose de lo que era", sendo, assim, um período de difícil determinação. No entanto, examina que os acontecimentos que o formam e as respostas a eles formuladas possibilitam individualizá-lo, sendo encarado, ainda, como de

\footnotetext{
${ }^{9}$ Importante, nesse sentido, é o movimento que Patrícia Funes (2006: 69)denomina como de "salvar lanación". Para a autora, na década em questão, o problema da nacionalidade se torna fundamental para as preocupações intelectuais. A ideia de "salvação" se configura a partir da imagem de crise, consequência da guerra mundial no pensamento, que junto ao colapso da ordem oligárquica, levouà revisão de pressupostos políticos, sociais e culturais.

${ }^{10}$ A respeito, analisa Funes (2006: 13): “Si los 'bárbaros' europeos se habían suicidado en una guerra, como proclamaba no sin desconsuelo José Ingenieros, el carácter de 'civilización' podia se revisado, incluso, invertido. Para José Vasconcelos, por ejemplo, la barbárie en la historia se había demonstrado más creativa como matriz de las civilizaciones. La modernidad latinoamericana, entonces, podia juzgarse con menos rigor y si no con autonomía, mucho más libremente".
} 
fundação de muitas tradições do pensamento e da práxis latino-americana. Muitos debates suscitados nos anos 1920, aos quais participa Mariátegui, perduraram na historiografia da região, o que indica a relevância de sua análise $^{11}$. Seu pensamento se insere, ainda, em uma longa tradição a respeito da identidade latino-americana e do movimento anti-imperialista que, juntamente com o marxismo dessa década ${ }^{12}$, aproximaram o Peru a outras formações culturais, trazendo complexidade à reflexão sobre nação einternacionalismo, presente em suas ideias. Funes (2006: 229), ademais, analisa quefrente à crise do paradigma eurocêntrico, os intelectuais latino-americanos buscaram não somente na Rússia, mas na China, Índia e Egito, por exemplo, analogias para pensar o subcontinente. Dessa forma, a América Latina começava a se pensar como "outro Ocidente".

Consideramos relevante explorar as relações entre "Ocidente", "Oriente"13 e América Latina, posto que essa discussão se apresentana obra de Mariátegui.

O lugar que o subcontinente ocupa nas antinomias leste-oeste ou nortesul, dentre os espaços periféricos e em relação aos centros dominantes (tanto econômicos quanto culturais) refere-se não somente à geografia ou a sua historicidade, mas à construção de uma identidade própria e de um

\footnotetext{
11 Também destacando as relações dos intelectuais latino-americanos e o processo de construção da identidade, Alberto Aggioe Marcos Sorrilha Pinheiro (2012: 39-40) defendem uma mudança na maneira desses sujeitos se relacionarem com o Estado e com a sociedade civil no pós-guerra. Para os autores, essa geração de intelectuais, na qual está inserido José Carlos Mariátegui, compartilhava a crença no protagonismo latino-americano e se posicionara ao lado dos setores dominados da sociedade, considerando que a identidade já não poderia mais ser pensada como unívoca, mas conflituosa e heterogênea. É um período ainda que inicia certa tradição esquerdista dos intelectuais latino-americanos, percorrendo todo o século XX.

${ }^{12}$ Para Rubén Jiménez Ricárdez (1978: s/p.), o pensamento de Mariátegui: "Entronca con aquellas tres corrientes del pensamiento progresista que existían en nuestros países hacia finales del siglo pasado y principios del actual: con la honda tradición de pensamiento democrático radical y antimperialista, que tuvo en Martí a su mejor representante; con el anarquismo, la ideología que orientó los albores de la lucha obrera; y con aquel socialismo - 'reformista y demócrata' y no marxista - que había surgido en Argentina desde el siglo XIX. Pero si la obra de Mariátegui entronca con esas tres corrientes, lo hace en actitud polémica y crítica. Se inserta en la tradición, pero para superarla, dando un nuevo tratamiento a sus temas. Logra, así, formular ex novo la visión de la realidad latinoamericana".

${ }^{13}$ Ao utilizarmos "Oriente" de forma genérica, estamos nos referindo aos países da Ásia e África. Na produção de Mariátegui, essa região está representada tanto nessa forma genérica quanto delimitada por um país específico.
} 
posicionamento nas relações de poder entre as nações, nos discursos sobre ela mesma e o "outro". A questão sobre "ser América Latina" está permeada pela complexidade na definição de um espaço e de uma culturadifícil de ser delineada ${ }^{14}$. Pertencendo historicamente a um "Ocidente", se insere também em um estado de dependência que a distancia e a difere desse, aproximando-a de um "Oriente" 15 .

Amiúde, os discursos do "Ocidente" sobre o "Oriente"foram construídos de forma a legitimar a dominação sobre o "outro" ${ }^{16}$, ou minimizar seu papel no processo histórico mundial. Como nos informa Martín Bergel(2006), se voltando principalmente para a Argentina, no decorrer do Oitocentos, intelectuais latino-americanos produziramuma representação dos povos orientais reforçando estereótipos racistas e uma visão de inferioridade. Contudo, nas primeiras décadas do século $\mathrm{XX}$, principalmente após o primeiro conflito bélico mundial, passaram a valorizar um destino e até uma identidade em comum. O imperialismo foi fundamental nesse período, desempenhando um processo de aproximação cultural e de referenciais político-ideológicos diferentes, ao mesmo tempo em que contribuía para a construção de umadada identidade latino-americana em nível continental ${ }^{17}$.O movimento antiimperialista, nesse decênio em questão, marcou expressivamente o pensamento político-social latino-americano (FUNES, 2006: 205) ${ }^{18}$.

\footnotetext{
${ }^{14}$ Apoiando-se em autores como Alain Touraine, Alain Rouquié, Gramsci e Juan Carlos Portantiero, Bernardo Ricupero (2003: 86-87) trata dessa questão voltando-se para o marxismo na América Latina.

${ }^{15}$ No âmbito das ideias, para Devés-Valdés (2018: 107), há similitudes no pensamento elaborado na América Latina e na Ásia desde o século XIX, por compartilharem ambas de uma"disjuntiva periférica".

${ }^{16}$ Como já conhecidamente analisado por Said (2007).

17 Sobre a mudança nas relações entre Ocidente-Oriente entre os latino-americanos, é emblemática a Revista de Oriente analisada por BERGEL (2006).

${ }^{18}$ Rafael Pinheiro de Araujo e Rafael Affonso de Miranda Alonso(2018: 148-149) também sublinham que: "Após a Revolução Mexicana e a vitória dos bolcheviques na Rússia, em outubro de 1917, difundiram-se uma série de iniciativas culturais, artísticas e intelectuais na região. Estas não só rediscutiram a história latino-americana e defenderam a edificação de novos laços identitários, como também adotaram um tom fortemente crítico à postura abertamente intervencionista dos Estados Unidos. Com isso [...] difundiu-se a proposta antiimperialista entre círculos militantes e intelectuais da região ao longo das décadas de 1920 e $1930 "$.
} 
Um exemplo de como Mariátegui abarcava essas questões, pode ser visto em seu comentário sobre a mensagem que o marroquino Abdel-Krim, no desdobramento da luta pela República de Rife, enviou aos latino-americanos em 1924, ano do centenário da batalha de Ayacucho. O socialista escreveuemVariedadesem 1925:

La nueva generación hispano-americana saluda en la empresa de Abd-el-Krim la repetición de la empresa de San Martín y de Bolívar. Y se da cuenta de que en Marruecos está en juego algo más que la simple independencia rifeña. Abd-el-Krim representa, en esa contienda, la causa humana (MARIÁTEGUI, 1988: 238).

Nesse trecho, vemos a celebração de "herois libertadores" e a ênfase de suas ações para a causa humana universal, que se relaciona às lutas de emancipação.A circulação e apropriação de ideias, por meio da chave antiimperialista, pode ser constatada também na formação da Alianza Popular Revolucionária Americana (APRA), por Víctor RaúlHaya de la Torre em 1924. Tendo como uma de suas referências o Kuomintang, propunha uma frente única formada pelos países latino-americanos contra o imperialismo exercido pelos Estados Unidos ${ }^{19}$.Quando mais tarde se converteu em partido político, tal proposta esteve no centro dos debates entre Mariátegui e Haya de la Torre acerca do caráter da revolução e foi uma importante discussão, na medida em que o modelo chinês se transformou em arquétipo para a atuação revolucionária latino-americana difundida pela Internacional Comunista (1919-1943).

Entendemos que seja importante também refletirmos sobre as diretrizes difundidas por esse órgão e sobre a apropriação do marxismo no contexto latino-americano e periférico, considerando-os como "os paradigmas intelectuais, os epistémé, as correntes filosóficas que interferem, direta e indiretamente, nas representações, nas visões de mundo, condicionando sistemas de percepção, de apreciação e de classificação" (SILVA, 2003: 19).

O movimento comunista, por meio da IC, voltou seu olhar para os países orientais e latino-americanos (chamados de atrasados, coloniais ou

\footnotetext{
${ }^{19} \mathrm{O}$ seu correspondente oriental se verifica em uma das unidades do Kuomintang, cujo nome era "Divisão Sandino" (BERGEL, 2006: 117).
} 
semicoloniais por este organismo) nos anos 1920, e juntamente com os movimentos nacionalistas e anti-imperialistas elaborou propostas e discutiu questões que estiveram no âmago do pensamento "mariateguiano", como as de etnia, do papel das burguesias e do campesinato. Contudo, as orientações da Terceira Internacional se distanciaram dessas realidades nacionais, homogeneizando o processo revolucionário no qual estas nações deveriam seguir $^{20}$. Nesse sentido, a organização enfrentou posicionamentos contrários ao seu, o que demonstra seu VI Congresso em relação à América Latina ou o II Congresso para os povos do Oriente, por exemplo.

Conforme lembra o historiador peruano Ricardo MelgarBao (2000: 4), o marxismo pode ser entendidoem três dimensões: como uma expressão civilizatória do Ocidente; como uma crítica ao capitalismo; e como objeto de tradução e apropriação ideológico-cultural de outros povos e contextos. De certa forma, essas dimensões estão presentes nas relações entre a Internacional Comunista, as "periferias" e o pensamento de José Carlos Mariátegui, que se aproximou dessa organização em seus últimos anos de vida ${ }^{21}$.

Embora a produção de Mariátegui não se enquadrar inteiramente no que Bergel (2006) denominou de "orientalismo invertido", uma análise preliminar das fontes indica a relevância que o Oriente assume em sua interpretação não somente da geopolítica mundial, mas para questões específicas das realidades periféricas, como a peruana.

Em Mariategui encontramos análises sobre a Turquia e a revolução de Mustafá Kemal, sobre a China desde sua revolução nacionalista de 1911, sobre o Egito e Zagloul Pachá, sobre o movimento swadeshi na Índia, sobre o Marrocos e a luta comandada por Abd-el-Krim, sobre a Palestina e a questão sionista e também sobre o socialismo no Japão, que apesar de não ser um país colonial, política ou economicamente - já que era na Ásia uma potência imperialista desde o século XIX -, era um exemplo de povo não-ocidental que

\footnotetext{
${ }^{20}$ Cf. RICUPERO, 2003 e ARICÓ, 1989. Também Leonardo Guedes Henn (2010), que analisa as diretrizes da IC formuladas para a América Latina.

${ }^{21}$ Os debates em torno da heterodoxia de Mariátegui em relação à IC são bastante conhecidos. Para uma breve exposição do tema cf. PERICÁS, 2011.
} 
buscou sua modernização com a assimilação de novas ideias que vinham do Ocidente. O Japão parece ser, para Mariátegui, o protótipo mais acabado do processo de ocidentalização e de transformação das estruturas sociais, políticas e econômicas que o imperialismo implicava. Assim, encontramos na produção do intelectual, reflexões relevantes envolvendo o Oriente e o Peru, que se dedicam à discussão acerca da tradição e do socialismo, do nacionalismo e do internacionalismo.

A pluralidade de atores que formularam"táticas" e "estratégias" contra a dominação, se posicionando nos espaços de poder, possibilita nos indagar, como sugere Eduardo Devés-Valdés, a respeito de uma cartografia do espaço intelectual da periferia dos anos $1920^{22}$. Suscitando, pari passu, algumas reflexões. Alguns objetivos mais amplos da pesquisa consistem em verificarse é possível a produção de Mariátegui contribuir para uma maior apreensão do ordenamento mundial por meio das regiões periféricas (ou seja, a partir dos mundos coloniais ou semicoloniais como eram chamados no período), sobretudo por meio do debate das ideias e propostas político-ideológicas surgidas face ao imperialismo; e também, se é possível discutir a identidade latino-americana no pós-guerra, refletindo sobre qual lugar Mariáteguiinsere a América Latina e, por sua vez, o seu próprio lugar de enunciação em seus discursos.

\section{Referências}

AGGIO, Alberto; PINHEIRO, Marcos Sorrilha. Os intelectuais e as representações da identidade latino-americana. Dimensões, Espírito Santo, n. 29, p. 22-49, 2012. Disponível em: $<$ http://periodicos.ufes.br/dimensoes/article/view/5396 > . Acesso em: 05 mar. 2020.

ALIMONDA, Héctor. Mariátegui: vanguardas, tradição e modernidade. Estudos Sociedade e Agricultura, Rio de Janeiro, v. 2, n. 2, p. 101-113, nov.

${ }^{22}$ Analisando as redes construídas entre os países periféricos, Eduardo Devés-Valdés (2011: 106) propõe uma cartografia desse espaço, atentando para a existência de uma "consciência periférica". Para esse autor ainda: "El pensamiento socialista-antiimperialista es el primer sistema eidético que permite imaginar redes intelectuales y políticas globales y, por poco tiempo, también lo permitieron alguns nacionalismos-anticoloniales, que apuntaban a buscar aliados em sus luchas, por sobre las marcas identitarias regionales". 
1994.

Disponível

em:

$<$ https://revistaesa.com/ojs/index.php/esa/article/view/41/43>. Acesso em: 30 jan. 2020.

AQUINO BOLAÑOS, Emigdio. José Carlos Mariátegui y elpensamientolatinoamericano de su época. Revista de Indias, Madrid, v. 60, n. 219, p. 437-452, 2000. Disponível em: $<$ http://revistadeindias.revistas.csic.es/index.php/revistadeindias/article/view/51 4/581>. Acesso em: 27 jul. 2019.

ARAUJO, Rafael Pinheiro de; ALONSO, Rafael Affonso de Miranda. As relações entre Estados Unidos e América Latina (1889-1930): da Primeira Conferência Pan-Americana ao anti-imperialismo latino-americano. Revista eletrônica da ANPHLAC, n. 25, p. 135-160, jul./dez. 2018. Disponível em: $<$ http://revistas.fflch.usp.br/anphlac/article/view/3060/2664>. Acesso em: 20 maio. 2019.

ARICÓ, José. O marxismo latino-americano nos anos da Terceira Internacional. In: HOBSBAWM, Eric. (Org.). História do Marxismo: o marxismo na época da Terceira Internacional: o novo capitalismo, o imperialismo, o terceiro mundo. Trad. Carlos Nelson Coutinho, Luiz Sérgio N. Henriques e Amélia Rosa Coutinho. 2 ed. Rio de Janeiro: Paz e Terra, 1989, 8 v, p. 419-459.

BAO, Ricardo Melgar. Mariátegui e a ocidentalização da política. Estudos de sociologia, São Paulo, v. 5, n. 9, p. 1-24. 2000. Disponível em: $<$ https://periodicos.fclar.unesp.br/estudos/article/view/190/186>. Acessoem: 05 mar. 2020.

BERGEL, Martín. Un caso de orientalismo invertido: la Revista de Oriente (1925-1926) y los modelos de relevo de la civilización occidental. Prismas, Bernal, v. 10, n. 1, p. 99-117, jun. 2006. Disponível em: $<$ https://www.redalyc.org/pdf/3870/387036781005.pdf > Acesso em: 05 mar. 2020 .

COMPAGNON, Olivier. O adeus à Europa: a América Latina e a Grande Guerra. Trad. Carlos Nougué. Rio de Janeiro: Rocco, 2014.

DEVÉS-VALDÉS, Eduardo. La circulación de las ideas, una conceptualización: el caso de la teologia latinoamericana en Corea del Sur. In: Costa, Adriane Vidal; Maíz, Claudio. (Orgs.). Nas tramas da "cidade letrada": sociabilidade dos intelectuais latinoamericanos $\mathrm{e}$ as redes transnacionais. Belo Horizonte: Fino Traço, 2018, p. 105-129.

Las redes de la intelectualidad periférica entre 1920 y 1940: intento de una cartografia y de un planteamiento teórico. Cuadernosdel CILHA, Mendoza, n. 14, 2011. Disponível em: 
<http://www.redalyc.org/articulo.oa?id=181721529005>. Acessoem: 20 maio. 2019.

FUNES, Patrícia. Salvar la nación: intelectuales, cultura y política en los años veinte latinoamericanos. Buenos Aires: PrometeoLibros, 2006.

HENN, Leonardo Guedes. A Internacional Comunista e a revolução na América Latina: estratégias e táticas para as colônias e semicolônias (19191943). São Paulo: Blucher Acadêmico, 2010.

LÖWY, Michael. (Org.). O marxismo na América Latina: uma antologia de 1909 aos dias atuais. 2 ed. rev. e ampl. São Paulo: Editora Fundação Perseu Abramo, 2006.

MARIÁTEGUI, José Carlos. El alma matinal y otras estaciones del hombre de hoy. 4 ed. Lima: Biblioteca Amauta, 1970, 3 v.

. La escenacontemporánea. 6 ed. Lima: Biblioteca Amauta, 1975, 1 v.

História de la crisis mundial. Conferencias (años 1923 y 1924). 11 ed. Lima: Biblioteca Amauta, 1986a, 8 v.

. Ideología y Política. 6 ed. Lima: Biblioteca Amauta, 1986b, 13 v.

PeruanicemosalPerú. 11 ed. Lima: Biblioteca Amauta, 1986c, 11 v.

Figuras y Aspectos De la Vida Mundial I (1923-1925). 9 ed.Lima: Biblioteca Amauta, 1988, 16 v.

. Sete ensaios de interpretação da realidade peruana. São Paulo: Expressão Popular, 2010.

O crepúsculo da civilização. In: Revolução Russa: história, política e literatura. São Paulo: Expressão Popular, 2012, p. 49-54.

MELIS, Antonio. Mariátegui, primer marxista de America. Latinoamerica. Cuadernos de cultura latinoamericana, UNAM, México, 1979, v. 95.

MITRE, Antonio. A parábola do espelho: Identidade e modernidade no Facundo Sarmiento. In: O dilema do Centauro: ensaios de teoria da história e pensamento latino-americano. Belo Horizonte: Editora UFMG, 2003, p. 39-70.

MORSE, Richard. Aberturas para o marxismo. In: O espelho de Prospero: cultura e ideias nas Américas. Trad. Paulo Neves. São Paulo: Companhia das letras, 1988, p. 96-111. 
PERICÁS, Luiz Bernardo. José Carlos Mariátegui e o Comintern. Lutas Sociais, São Paulo, n. 25/26, p. 176-190, $2^{\circ}$ sem. de 2010 e $1^{\circ}$ sem. de 2011. Disponível em: <https://revistas.pucsp.br/ls/article/view/18589/13789>. Acesso em: 27 jul. 2019.

RICÁRDEZ, Rubén Jiménez. Mariátegui: teoría y práctica del marxismo en América Latina. Cuadernos Políticos, México, D. F, n. 17, p. 80-101, jul./set. 1978.

Disponívelem: $<$ https://www.archivochile.com/Ideas_Autores/mariategui_jc/s/mariategui_s00 80.pdf>. Acesso em: 02 jun. 2018.

RICUPERO, Bernardo. Existe um pensamento marxista latino-americano? In: COGGIOLA, Osvaldo. (Org.). América Latina: encruzilhadas da história contemporânea. São Paulo: Xamã, 2003, p. 81-100.

SAID, Edward. Orientalismo: o Oriente como invenção do Ocidente. São Paulo: Companhia das letras, 2007.

SILVA, Helenice Rodrigues da.A História Intelectual em questão. In: LOPES, Marcos Antônio. (Org.). Grandes nomes da história intelectual. São Paulo: Contexto, 2003, p. 15-25.

WASSERMAN, Cláudia. História intelectual: origem e abordagens. Tempos Históricos, Paraná, v. 19, n. 1, p. 63-79, $1^{\text {o }}$ sem. de2015. Disponível em: $<$ http://e-

revista.unioeste.br/index.php/temposhistoricos/article/view/12762/8823 >.

Acesso em: 04 mar. 2020. 